\title{
PENDIDIKAN KAUM SUFI DI INDONESIA (Materi dan Metode Pendidikannya)
}

\author{
Oleh. \\ Suheri Sahputra Rangkuti \\ Universitas Islam Negeri Sunan Kalijaga Yogyakarta \\ suheriray@gmail.com
}

Sufis are part of the nomenclature of Islam in Indonesia. its existence which is already old even almost simultaneously with the entry of Islam into Indonesia certainly has involvement and contribution in building the nation. In addition, the pattern of tarekat in Indonesia which does not negate the worldly orientation is able to encourage change. Therefore, this article wants to reveal the material and methods of education to contribute ideas to enrich the treasures of Islamic education.

\section{Key Word: Sufi, Material, Method, Education}

\begin{abstract}
Abstrak
Kaum sufi adalah bagian dari nomenklatur ke-Islmaan di Indonesia. keberadaannya yang sudah tua bahkan hampir berbarengan dengan masuknya Islam ke Indonesia sudah barang tentu memiliki keterlibatan dan kontribusi dalam membangun bangsa. Di samping itu, pola tarekat di Indonesia yang tidak menegasikan orientasi keduniaan mampu memberi semangat perubahan. Oleh karenanya, artikel ini ingin mengungkap materi dan metode pendidikannya guna memberi sumbangan pemikiran untuk memperkaya khazanah pendidikan Islam.
\end{abstract}

\section{Key Word: Sufi, Materi, Metode, Pendidikan}

\section{A. PENDAHULUAN}

Tsawuf merupakan satu dari sekian banyak kahzanah yang ikut mewarnai dan membangun peradaban umat Islam. Tasawuf sebagai manhaj berfikir adalah hal yang baru dalam dunia Islam, ia baru dikenal dan merebak abad kedua hijriyah. Sebelumnya, para ilmuan Islam menyibukkan diri dan terpaku kepada kajian-kajian teolgis (aqidah) dan formalis (syariah). Kehadiran tasawuf dalam pentas pemikiran Islam dilatarbelakangi oleh suasana hiruk pikuk perdebatan dan pertentangan antara madzhab di tubuh umat Islam.
Hiruk pikuk yang diperankan oleh dua kubu alur pikir yang berseberangan, yaitu, antara Ahlu ar-Ro'yi (Qadariyah dan Muktazilah) dengan Ahlu al-Hadis (Jabariyah dan Ahlusunnah) melahirkan aliran baru yang mengambil concernt terhadap kajian tentang kemanusiaan. Dengan begitu, aliran manhaj baru dalam pemikiran Islam ini, muncul dan menjadi gerakan spritual yang menembus batas-batas sempit. Sehingga meneropong relasi manusia dengan Tuhan secara utuh, 
meninggalkan simbol-simbol formal agama. ${ }^{1}$

Kemunculan berpikir taswauf juga tidak lepas dari sejarah hingar bingar politik masa lalu, pertentangan antara pendukung fanatis yang menyuarakan Ali sebagai khalifah dengan pihak oposisi yaitu kahawrij. Kontraksi kedua aliran ini menjadi makin ekstrim setelah keduanya memproklamirkan diri sebagai kelompok yang paling benar, sampai berujung kepada upaya untuk saling membinasakan dan bahkan memakan korban dari kedua belah pihak. Kelompok yang tidak pro kepada kedua belah pihak tersebut, kemudian menjadi tokoh utama dalam membidani lahirnya tasawuf dan orang yang menggelutinya disebut dengan sufi. Para tokohnya antara lain, Abu Dzar alGhifari, Salman al-Farisi, Ammar Bin Yasir dan Huzaifah Bin Yaman. ${ }^{2}$ Pada masa selanjutnya, kelompok tasawuf mulai memperlihatkan gerakannya pada masa penguasa Khalifah Bani Umayah (661-750) sebagai antitesa terhadap perilaku khalifah dan keluarganya yang tidak lagi mengindahkan ajaran-ajaran Islam. ${ }^{3}$

Islam di Indonesia merupakan salah satu dari nomenklatur keislaman yang banyak mengadopsi nilai dan

1 Ummu Salamah, Sosiologi Tarekat, Menjejaki Trasdisi dan Amaliah Spritual Sufi, (Bandung, Humaniora, 2005), v.

${ }^{2}$ Nor Huda, Islam Nusantara: Sejarah Sosial Intelektual Islam Di Indonesia, Cet. 1. (Sleman, Jogjakarta: Ar-Ruzz Media: Didistribusikan oleh Ar-Ruzz Media Group, 2007), 243.

${ }^{3}$ Saifuddin Zuhri, Tarekat Syadziliah, Dalam Perspektif Perilaku Perubahan Sosial, (Yogyakarta, Teras, 2011), 2. praktik kesufian dari timur tengah. Hal ini dikarenakan penetrasi Islam di masa belakangan lebih banyak dilakukan oleh para guru dan pengembara sufi yang sejak akhir abad ke-12 datang dalam jumlah yang semakin banyak ke Nusantara. Ditambah lagi pada abad ke-15, banyaknya orang Nusantara yang menimba ilmu dan naik haji, yang mengkhususkan penggalian ilmu di Madinah dan Makkah, pada saat itu kajian yang paling mencolok adalah hasil dari harmonisasi antara syariat dan tasawuf. Setelah mereka pulang dari Haramain, mereka menyebarkan dan mengajarkan ilmu agama sesuai dengan apa yang mereka dapati di sana. $^{4}$

Hal yang menarik dan penting dalam konteks pembahasan ini adalah dalam perkembangan tasawuf, baik sebagai sebuah konsep pemikiran maupun sebuah praktik dan gerakan, sudah pasti membutuhkan dan mengembangkan satu sistem pendidikan yang khas di mana persoalan spiritual mendapat tempat paling dominan. Pada gilirannya, perkembangan ini melahirkan ajaranajaran dan bentuk pendidikan di kalangan sufi, yang merupakan fenomena besar dan tidak mungkin diabaikan dalam kajian dunia pendidikan Islam. Dari penjelasan di atas, ada beberapa hal yang patut untuk diangkat dan dipertanyakan. Yaitu, bagaiamana Materi dan bentuk pendidikan kaum sufi di Indonesaia.

4 Azyumardi Azra, Jaringan Ulama Timur Tengah dan Kepualauan Nusantara, Abad XVII dan XVIII, (Bandung, Mizan, 1998), 17 


\section{B. SEJARAH SUFISME MASUK KE INDONESIA}

Masuknya Islam ke Indonesi menjadi sebuah data utama yang harus digali, guna melihat, apakah sufisme dibawa oleh kelompok penyebar Islam ke Indonesia. Hal ini begitu penting kendati dalam menetukan kapan dan darimana Islam datang ke tanah air, mengerucut kepada tiga teori. Hal ini terjadi karena adanya fakta dan argumen kuat dari masing-masing pemegang teori untuk membuktikan kebenaran dari alur sejarah yang dimiliki oleh pembangun teori tersebut. Ketiga teori itu ialah teori Gujarat, Makkah, Persia.

Pertama, teori Gujarat, diduga kuat peletak dasar teori ini adalah Snouck Hogrounje. Snouck dalam Suryanegara, menitik beratkan pandangannya ke Gujarat karena kurangnya fakta yang menjelaskan peranan bangsa Arab dalam penyebaran Islam di Nusantara, selanjutnya, ia menegaskan, hal ini didasari oleh hubungan dagang Indonesia dengan India telah lama terjalin. Kedua, teori Makkah, teori ini lahir dari kritik Hamka terhadap teori Gujrat, Hamka sebagai peletak teori menolak pandangan yang mengatakan bahwa Islam masuk ke Nusantara pada abad ke-13 dan datang dari Gujarat. Ia beralasan, pada abad ke-13 sudah berdiri kekuasaan politik Islam. Menurutnya, Islam sudah masuk ke Nusantara pada abad ke-7. Bukti yang ia ajukan ialah, bahwa Makkah pada abad ke-7 didominasi oleh madzhab Syafi'i, dan ternyata yang menyebar di Indonesia adalah madzhab Syafi'i, baginya, hal inilah yang menandakan bahwa orang Makkah dikala itu sudah datang ke-Nusantara. Ketiga, teori Persia, pembangun pandangan ini adalah, P.A. Hossein Djadiningrat. Teori ini lebih menitik beratkan tinjauannya kepada kebudayaan yang hidup di kalangan masyarakat Islam Indonesia, ia melihat adanya kesamaan kebudayaan antara Islam di Persia dan Indonesia, mulai dari hari-hari besar yang dirayakan, kesamaan bentuk ajaran kesufian sampai kepada beberapa istilah yang sering dipakai dalam keagamaan. ${ }^{5}$

Dari ketiga teori di atas, teori yang ketiga memperlihatkan adanya relasi masa Islam awal di Indonesia dengan kesufian sebagai ajaran yang dibawa oleh orang-orang Persia yang menyebarkan Islam di Indonesia. Adanya anggapan itu didukung juga dengan corak aliran sufi di masa awal yang menjadi perhelatan pemikiran di antara kalangan kaum sufi di Aceh, yaitu, sama-sama memakai paham wahdatul wujud persis pahamnya alHallaj dari Persia. Meski demikian teori nomor tiga di atas, tidak sepenuhnya benar, dengan alasan, bahwa, Hamzah Fansur orang yang pertama mendapatkan ijazah tarekat di Ayuthia ibu kota Muangthai dari orang Persia dan India. Selanjutnya, ia membawanya ke-Aceh dan dalam pada

5 Ahmad Mansur Suryanegara, Menemukan Sejarah: Wacana pergerakan Islam Di Indonesia, (Bandung, Mizan, 1998), 85-87. 
itu terjadi penyebaran lewat nuansa pendidikan yang ia lakukan dengan para muridnya. ${ }^{6}$ Dalam konteks ini, tibanya Islam di Nusantara tidak berbarengan dengan bentuk kesufian yang dibawa. Akan tetapi, dapat dikatakan, aliran tarekat yang pertama kali tiba dan berkembang di Indonesia adalah, aliran tarekat wahdatul wujud yang memiliki kesamaan dengan bentuk kesufian/tarekat yang berkembang di Persia.

Pada abad 17 khususnya, doktrin wujudiyah ini pernah menjadi bahan perdebatan di kalangan para ulama sufi itu sendiri. selain karena ada faktor sosio-politik saat itu yang mempengaruhi masing-masing pihak yang berselisih, adanya perbedaan interpretasi dalam memahami ontologi dari wujudiyah, menambah jarak perselisihan di antara para pakar sufi waktu itu. Demikian sengitnya kontroversi itu, hingga mengakibatkan terjadinya sebuah teragedi aceh, yakni pembakaran karya-karya mitis Hamzah Fansuri dan Samsudin as-Sumatrani yang dilakukan oleh ar-Ranary dengan pengikutnya. Berujung pada pengejaran dan pembunuhan terhadap para pengikut yang tidak mau meninggalkan ajaran tersebut. ${ }^{7}$

Dapat diakatakan, perbincangan kesufian di masa itu sudah menjadi trandingtopic dan mengemuka sehingga membentuk persepsi dan spektrum baru dari masyarakat dalam kehidupan keberagamaan mereka.

${ }^{6}$ Huda, Islam Nusantara, 289.

${ }^{7}$ Oman Faturrahman, Menyoal Wahdatu Wujud, Kasus Abdurrauf Singkel Abad 17, (Bandung, Mizan, 1999), 21.
Artinya, tarekat dengan segala komponennya, baik ajaran, aliran dan praktik sudah bersentuhan dengan masyarakat sejak dulu.

\section{CORAK PEMIKIRAN TASAWUF DI INDONESIA}

Menyoroti ajaran tasawuf di Indonesia, tidak bisa terlepas dari metamorfosis tarekat yang diterjemahkan dan diaktualisasikan dalam bentuk yang berbeda, tergantung pada konsep ajaran dan tarekat yang dianut. Di satu sisi istilah tasawuf dan tarekat memiliki perbedaan, namun antara tasawuf dan tarekat tidak bisa dipisahkan. Tarekat adalah metode praktis sebagai latihan dan pengamalan ajaran-ajaran dalam tasawuf. ${ }^{8}$ Dalam versi yang lebih lengkap, tarekat didefenisikan sebagai latihan praktis yang dimaksud yaitu, dengan meniru cara berpikir, perasaan dan tindakan menuju tahapan-tahapan dan keadaan untuk mencapai hakikat sesuai dengan pengetahuan dan pengalaman guru mursyid. ${ }^{9}$

Dapat dikatakan, geneologis dari corak tarekat di Indonesaia di level puncak adalah hasil dari perkawinan corak tasawuf falsafi dengan corak tasawuf sunni. Pada mulanya corak tasawuf yang menjadi dominian adalah corak falsafi. Lalu kemudian disusul oleh tasawuf yang bercorak sunni. Kedatangan tasawuf sunni menjadi semacam koreksi atas pemikiran

${ }^{8}$ Zulkifli, Sufism in Java: The Role Of The Pesantren In The Maintenance Of Sufism In Java, Seri INIS 40 (Jakarta: INIS, 2002), 28.

${ }^{9}$ MartinVan Bruinessen and Julia Day Howell, Urban Sufism (Jakarta: Rajawali Pers, 2008), 413. 
tasawuf falsafi yang menurut anggapan para tasawuf sunni pemikiran falsafi lebih manut kepada Ibn 'Arabi, al-Jili dan bahkan al-Hallaj. ${ }^{10}$ Koreksi yang dilakukan hanya merenovasi bagianbagian yang menurut tasawuf sunni bertentangan dengan aqidah dan terlalu ekstrim memahami relasi Tuhan dengan manusia. Namun, pada bagian yang lain, apalagi yang menyangkut dengan teknis meditasi, tidak banyak mengalami perubahan.

Menurut Mulkhan, anggapan tidak baik yang diberikan oleh ahli sunnah/ahli syariat kepada kaum sufi dengan memberi label telah menyimpang dari ajaran Islam murni, merupakan kesalahpahaman. Lanjut ia tegaskan, padahal tidak demikian, sesungghuhnya yang terjadi adalah titik berat dalam memandang aturan Islam atau syariat yang lebih ditekankan pada dimensi esoterik dan etik dengan tetap memenuhi aturan formal syariat. ${ }^{11}$ Anggapan ini juga, agaknya, bagian dari antitesa dari kecendrungan sufi menafsirkan nash-nash agama dari sudut kebathinan. ${ }^{12}$ Dengan merebaknya tasawuf al-Ghazali, menjadi semacam vitamin baru atau benang merah antara corak falsafi dan sunni dikalangan sufi Nusantara.

\footnotetext{
${ }^{10}$ Sokhi Huda, Tasawuf Kultural: Fenomena Shalawat Wahidiyah, Cet. 1. (Yogyakarta: LKiS : Distribusi, LKiS Pelangi Aksara, 2008), 79.

${ }^{11}$ Abdul Munir Mulkhan, Neo-Sufisme Dan Pudarnya Fundamentalisme Di Pedesaan, Cet. 1. (Yogyakarta: UII Press Yogyakarta, 2000), 97.

${ }^{12}$ Simuh, Sufisme Jawa: Transformasi Tasawuf Islam Ke Mistik Jawa, Cet. 1. (Yogyakarta: Yayasan Bentang Budaya, 1995), 44.
}

Perbedaan pola pandang dalam menganalisa tasawuf cendrung terjadi tarik menarik antara ahli sufi dan ahli syariat hingga saat ini. Karena memliki konsen dan pijakan yang berbeda. Namun penempatan atau pemaduan dua dimensi tersebut menjadikan sufi lebih akomodatif terhadap keberagamaan masyarakat disampingnya.

\section{MATERI DAN METODE PENDIDIKAN KAUM SUFI DI INDONESIA}

Perkembangan sufisme pada akhirnya melahirkan beragam pendidikan tarekat yang menyebar dan dianut oleh muslim Indonesia. Dari 44 yang diakui sebagai mu'tabaroh oleh para ulama, hanya 7 yang umum dipakai di Indonesia, yaitu, Qodiriyah, Naqsyabandiyah, Tijaniah, Syadziliah, Kholidiyah, Syattariyah dan Kholwatiyah. Perkembangan tarekat ini bukan hanya menandai kuatnya pembinaan keagamaan Islam Indonesia melalui praktek ritualnya, tetapi juga bersinggungan dengan perkembangan pendidikan Islam sendiri sebagai media pengembangan Islam di Indonesia. ${ }^{13}$

Lebih lanjut, akan dijelaskan bentuk ajaran dan metode pendidikan 2 tarekat yang mayoritas di anut oleh kaum sufi di Indonnesia:

\section{Tarekat Qadiriyah}

Tarekat Qadiriyah didirikan oleh Abdul Qadir al-Jailani, yang terkenal dengan sebutan Sayikh Abdul Qadir al-

13 Endang Turmudzi, Perkembangan Sufisme dan Kebangkitan Tradisionalisme, Jurnal Multikultural \& Multireligius, Vol.X 4 Oktober 2011, 784. 
Jailani al-Ghaust. Disebut dengan alGhaust karena diyakini sosoknya sebagai penghulu Waliyullah di masanya. Tarekat in menempati posisi yang amat penting dalam sejarah spritualitas Islam, karena bukan hanya sebagai pelopor lahirnya tarekat di kalangan umat Islam namun tarekat ini juga diyakini sebagai payung dari lahirnya tarekat-tarekat yang lain. ${ }^{14}$ Tarekat Qadiriah, sepeninggal Abdul Qadir disebarluaskan oleh anakanaknya. sehingga tarekat ini menyebar keberbagai negara, yang pada mulanya hanya berada di Baghdad saja. penyebaran itu meliputi, Syiria, Turki, Kamerun, Congo, Uni Soviet, Indonesia serta tempat-tempat lainnya. ${ }^{15}$ Sebgaimana telah disinggung di atas, menurut Snouck Horgronje, yang mendapat ijazah tarekat Qadiriyah yang pertama adalah Hamzah Fansur, yang ia terima langsung dari sufi Persia dan India. ${ }^{16}$

\section{Misi Pendidikannya}

Dalam pandangan Abdul Qadir al-Jailany, manusia sebagai makhluk sudah sepantasnya berserah kepada Tuhan dengan cara memburu kesadaran Ilahi. Dengan begitu menurutnya, manusia akan terarah dari ketergantungan dari simbol-simbol kebahagian yang berwujud materi kepada kesenangan yang hakiki. Karena tiada kebahagiaan yang paling nikmat selain ketenangan spritual yang

\footnotetext{
${ }^{14}$ Sri Muliyati, Mengenal \& Memahami Tarekat-Tarekat Muktabarah Di Indonesia (Jakarta: Kencana, 2005), 26.

${ }^{15}$ Ummu Salamah, Sosialisme Tarekat Menjejaki Tradisi Dan Amaliah Spritual (Bandung: Humaniora, 2005), 106.

${ }^{16}$ Huda, Islam Nusantara, 289.
}

membuat akrab kepada sumber segala kekuatan. ${ }^{17}$

$$
\text { Ajaran Abdul Qadir al-Jailany }
$$
selalu menekankan pada kesucian diri dari obsesi keduaniaan. Oleh karenanya, ia memberikan beberapa petunjuk ajaran untuk mencapai kesucian diri yang tertinggi. Adapun beberapa ajaran tersebut adalah, taubat, zuhud, tawakal, syukur, ridha, dan jujur. $^{18}$

Kurikulum yang dibangun oleh Abdul Qadir al-Jailany untuk mecapai visi misi yang ia tawarkan, yaitu, sebagai manusia yang memiliki spritual tinggi dan mewujudkan kedekatan manusia dengan sang penciptanya. Abdul Qadir al-Jailany membuat tahapan yang sesuai dengan jenjang kualitas manusianya. Hal ini terlihat dari penempatan setiap hirarki materi yang semakin ke atas semakin memiliki bobot dan kedalaman. Artinya, bagi sufi pemula di awali dengan kelas taubat sampai seterusnya.

\section{Prinsip Ajaran, Materi dan Metode Pembelajarannya}

a. Kelas Taubat

Di level ini materi yang diajarkan menyangkut seputar penegasan pentingnya taubat. Abdul Qadir al-Jailany memberikan pengajaran dalam bentuk metode ibrah dengan pendekatan perumpamaan-perumpamaan.

Dalam pengajarannya di level taubat, Abdul Qadir al-Jailany menganggap taubat bagaikan air yang menghilangkan najis, begitu

${ }^{17}$ Muliyati, Mengenal \& Memahami Tarekat-Tarekat Muktabarah Di Indonesia, 38. ${ }^{18}$ Ibid. 
juga taubat menghilangkan dosa dan kotoran maksiat. Salah satu proses pembelajaran yang terekam pada kelas taubat, yaitu, termaktub dalam wasiat yang ia katakan kepada muridnya. Ia berwasiat " wahai anakku, janganlah kamu berputus asa untuk mendapatkan rahmat Allah dengan kemaksiatan, tetapi basuhlah najis yang ada pada baju agamamu dengan air taubat, konsistenlah terhadapnya dan ikhlaslah di dalamnya". ${ }^{19}$

Dalam praktiknya, taubat oleh Abdul Qadir al-Jailany dibagi kepada dua macam, (1) taubat yang berkaitan dengan hak sesama manusia (2) dan taubat yang berkaitan dengan hak Allah. Dalam pelaksanaannya, taubat yang pertama, tidak akan terealisasi kalau tidak meminta maaf secara langusung, mengembalikan hak orang lain yang pernah dirampas kepada pemiliknya.

Selanjutnya, ia juga memberi peringatan dampak orang yang tidak melakukan taubat. Menurutnya, orang yang tidak menaubati kesalahan dan bahkan cendrung terjerumus tanpa memerdulikan bahwa itu kesalahan, maka, meskipun seorang itu ahli dan pakar, dikhawatirkan orang tersebut hanya dikategorikan munafik dan zindiq. ${ }^{20}$

b. Kelas Zuhud

Zuhud menurut Abdul Qadir al-Jailany ada dua, pertama, zuhud

${ }^{19} \mathrm{Abdu}$ al-Qadir al-Jailany, Fathu ArRabbany Wal Faidhu Ar-Rahmany (Lebanon: Dar ar-Rayyan at-Turast, t.th.), 15.

${ }^{20}$ Ibid., 128. hakiki, yaitu, zuhud yang mengeluarkan dunia dari hatinya, yang kedua, zuhud zhahir/lahir, yaitu, mengeluarkan dunia dari hadapannya. Abdul Qadir al-Jailany juga sering mempertentangkan antara zuhud dan syahwat. Sebagaimana dalam buku yang ia susun yang merupakan bagian dari materi bahan ajarnya. Ia mengatakatan, hilangnya rasa zuhud karena dikikis oleh syahwat, ia tambahkan lagi, bukanlah kondisi diri diliahat dari bentuk dari apa yang dipakai dan yang dimakan melainkan diri dibentuk dari kondisi hati yang penuh kezuhudan. ${ }^{21}$

Materi tentang zuhud dalam permbelajarannya, mengarah kepada titik terdalam dari pengendalian pengaruh dunia, yaitu, menolak ambisi kepada keduniaan. Dalalm pembelajarannya juga, ia memberikan kerangka pengamalan langsung secara peraktis. Misalnya, dengan mempertentangkan zuhud dengan hawa nafsu, sementara nafsu itu dikekang oleh puasa lalu ia menyuruh agar berpuasa. Atau dengan cara-cara lain yang bisa mengekang nafsu.

Dalam pengjarannya yang menggunakan metode perumpaan, dan mau'izhah ia mengatakan,

Cambuklah nafsu dengan cambuk lapar, cegahlah ia dari bagiannya dan tempatkan ia dalam memenuhi hak-haknya. Seretlah ia dan jangan takut akan pisau dan pedangnya. Pedangnya hanya

\footnotetext{
${ }^{21}$ Ibid., 19.
} 
sebentuk kayu, bukan besi baja. Nafsu hanya berbicara tanpa berbuat, dusta tanpa ketulusan, janji tanpa pernah ditepati. Nafsu tidak memiliki cinta kasih, dan terus berjalan tanpa memiliki kampung halaman. Iblislah yang menjadi panglimanya. Iblis tidak mempunyai kekuatan apa-apa melawan orangorang beriman yang benar-benar tulus memusuhi dan melawannya, apalagi hawa nafsu. ${ }^{22}$

c. Kelas Tawakkal

Syaikh Abdul Qadir alJailany, dalam pengajarannya, menekankan tawakkal ia mengutip makna hadis Nabi. Ia mengatakan, "bila seseorang menyerahkan dirinya secara penuh keapda Allah, maka Allah akan mengaruniakan apa saja yang diminatinya. Begitu juga sebaliknya, bila dengan bulat ia menyerahkan dirinya kepada dunia, maka Allah akan membiarkan dirinya dikuasai oleh dunia. $^{23}$ Materi ini terambil dari makna hadis yang mengatakan, apabila ingatan manusia telah condong kepada dunia, maka ingatannya kepada akhirat akan berkurang.

Di dalam materi tawakkal, Abdul Qadir al-Jailany banyak memuat motivasi agar jangan malas. Di dalam materi ini pula ia banyak menyampaikan ceramah yang mengandung larangan, misalnya, jangan malas, jangan banyak makan,

${ }^{22}$ Syekh 'Abdul Qadir al-Jailani, Lautan Hikmah Kekasih Allah, Terj. Kamran As'ad Irsyadi, (Jogjakarta: Diva Press, 2007), 157.

${ }^{23}$ Muliyati, Mengenal \& Memahami Tarekat-Tarekat Muktabarah Di Indonesia, 40. jangan banyak tidur dan jangan bergaul dengan orang-orang yang menyiakan-nyiakan waktunya.

Di samping itu, Abdul Qadir al-Jailany juga membuat konsep tahapan dan langkah sebagai latihan untuk memasuki pengalaman tawakkal, pertama, mengenal Tuhan dengan seluruh sifatnya, kekuasaannya, sampai kepada ilmunya yang bersumber dari kekuasaannya. Hamba pada tahap ini, adalah hamba yang berada pada maqam pertama. Kedua, menetapkan sebab akibat. Ketiga, menghujami hati dengan pentauhidan, bahkan hakikat tawakkal itu adalah tauhid. Maka tidak mungkin orang bertawakkal tanpa memperdalam tauhid. ${ }^{24}$

d. Kelas Syukur

Syukur menurut Abdul Qadir al-Jailany bukan hanya ucapan dengan lidah dan pengakuan di hati saja. Justru syukur yang paling besar tantangannya adalah syukur dengan anggota badan. Syukur dengan menggunakan anggota badan mendapat perhatian besar dari Abdul Qadir al-Jailany hingga ia membuat metode mengamalkan syukur dalam bentuk nyata.

Pertama, syukur dengan pengakuan hati dan lidah ialah dengan berupaya bersipat tenang dan selalu menganggap diri sebagai

${ }^{24}$ Sa‘īd ibn Misfar ibn Mufrah Qahțānī, Al-Shaykh 'Abd Al-Qādir Al-Jīlān̄̄ WaĀrā'uhu Al-I'tiqādìyah Wa-Al-Șüfìyah: 'ard Wa-Naqd 'alá Daw' 'aqìdat Ahl Al-Sunnah Wa-Al-Jamā'ah, al-Ṭab'ah 1. (al-Riyāḍ: Tawzī‘ Mu'assasat al-Jarīsī lil-Tawzī‘', 1997), 608 . 
orang yang lemah dan hina. Kedua, syukur melalui anggota badan, yaitu, dengan menggerakkan seluruh anggota badan untuk beramal hanya kepada Allah bukan kepada makhluk, ketika beramal mengosongkan hati dari anganangan dan hawa nafsu. ${ }^{25}$

e. Kelas Sabar

Abdul Qadir al-Jailany membagi sabar kepada tiga bagian, pertama, bersabar kepada Allah dengan melaksanakan perintahnya dan menjauhi perintahnya, kedua, bersabar bersama Allah, yaitu, bersabar terhadap ketetapan Allah dan perbuatannya kepadamu dari segala macam kesulitan dan musibah, ketiga, bersabar terhadap rezeki, jalan keluar, kecukupan, pertolongan dan pahala yang dijanjikan di negeri akhirat. ${ }^{26}$

Abdul Qadir al-Jailany melakukan pembagian ini untuk merangsang nalar para murid untuk bisa menggunakan sabar pada posisi yang tepat. Karena sabar dalam dunia sufi banyak disalah artikan. Di samping itu, sabar kadang dijadikan alasan untuk tidak bergerak dan melawan segala penindasan dan kezaliman. Dalam pembagian ini jelas sekali posisi sabar memberi argumen yang menegasikan kelemahan, ketakutan dan kemalasan.

f. Kelas Ridha

Dalam kelas ini, Abdul Qadir al-Jailany memberi pengeuatan, semestinya seorang hamba menerima apa yang dipilihkan Allah kepadanya. Sesorang harus meyakini bahwa apa yang dipilihkan Allah kepadanya merupakan yang terbaik baginya. Selanjutnya, ia menyeru, "wahai anak adam apapun yang kamu rasa tidak baik dari apa yang telah Allah tentukan untukmu, sebenarnya, itulah yang terbaik, kamu mesti menerimanya dengan senang hati maka bertakwalah kepada Allah". ${ }^{27}$

Abdul Qadir al-Jailany dalam mendidik murid-muridnya, mengajak unutk rela sepenuh hati. Kerelaan merupakan upaya untuk menghilangkan segala keresahan dengan keadaan. Berangkat dari sini, Abdul Qadir al-Jailany memusatkan pendidikannya dengan sentuhan-sentuhan narasi yang menembus sampai kedalam jiwa. Di samping, pengajaran dengan metose ceramah, tentu, ia juga menggunakan metode yang lain dalam latihannya yang bisa ditemukan dalam buku-buku yang membahasa tentang kelas ridha. Berhubung ini hanya makalah, maka penulis hanya menyebutkan sedikit saja.

\section{g. Kelas Jujur}

Selain jalan hidup, kejujuran bagi kaum sufi juga napas dari hidupnya. Kelas ini adalah kelas terakhir dari perkuliahan yang dibuka oleh Abdul Qadir al-Jailany dalam tarekat Qadiriyah. Artinya, kelas jujur merupakan kelas tertinggi dari kelas-kelas 
sebelumnya. Karena kelas ini adalah penentu apakah kelas-kelas yang dibawahnya berjalan secara dengan baik. Bisa dikatakan kelas jujur memayungi segala kelas yang dibawhnya.

Ia membuka kelas jujur dengan musatkan perhatian pada usaha untuk selalu jujur. Ia mengangkat sebuah hadis sebagai landasan kelas ini, tetaplah dengan kejujuran, kerena sesungguhnya kejujuran mengajak kepada kebaikan dan kebaikan menjembatani kita masuk surga...... Dari Ibn Mas'ud,. Ia memperkuat dengan penjelasannya, jujur itu tiang segala urusan, dengan jujur urusan jadi sempurna, dengan jujur urusan jadi teratur. ${ }^{28}$

\section{Tarekat Naqsyabandiyah}

Tarekat Naqsabandiyah didirikan oleh seorang ulama dan pemuka tasawuf yang terkenal, yakni, Muhammad bin Muhammad Baha ud-Din al-Uwais al-Bukhari Naqsabandy. Dilahirkan di sebuah desa yang disebut dengan Qashrul Arifah, kurang lebih 4 mil dari Bukhara tempat lahir Imam Bukhari. Sama seperti pendiri tarekat lainnya, pendiri tarekat Naqsyabandiyah juga seorang ilmuan yang banyak menimba ilmu agama dari berbagai disiplin ilmu. ${ }^{29}$

Di duga kuat Syeikh Yusuf Makassari yang memperkenalkan tarekat Naqsyabandiah keIndonesia. Ia menerima ijazah dari

\footnotetext{
${ }^{28}$ Ibid., 633.

${ }^{29}$ Muliyati, Mengenal \& Memahami Tarekat-Tarekat Muktabarah Di Indonesia, 89.
}

Syaikh Muhammad 'Abd al-Baqi di Yaman. Kemudian mempelajari tarekat ketika berada di Madinah di bawah bimbingan Syaikh Ibrahim al-Kurni. ${ }^{30}$ Pada mulanya tarekat ini berkembang di Samarkand Bukhara melintas ke Afganistan yang kemudian sampai ke India. Dari india melintas hingga ke Yaman dan Haramain. Yusuf Makassari yang menimba ilmu di sana kemudian bersentuhan langsung dengan para guru tarekat tersebut, sebagaimana telah diutarakan di atas.

\section{a. Misi Pendidikannya}

Muhammad Baha ud-Din alUwais al-Bukhari Naqsabandy sangat memperhatikan kesederhanaan, latihan moral, spritual murid-muridnya. Ia sangat konsen terhadap pengubahan perilaku, bahkan ia pernah minta maaf kepada seseorang dengan mengatasnamakan muridnya, karena muridnya tersebut menggosokkan wajah ketembok rumah tanpa minta izin kepada pemiliknya. ${ }^{31}$

Ciri menonjol dari tarekat ini adalah mengikuti syariat secara disiplin, keseriusan beribadah dengan menyebabkan penolakan kepada musik dan tari dan lebih menyukai berzikir dalam hati, mendekatkan negara pada agama. ${ }^{32}$

\section{b. Metode Pembelajaran}

Sepertinya tarekat Naqsyabandiyah lebih memusatkan pembelajarannya kepada latihanlatihan. Boleh jadi pemberian materi

\footnotetext{
${ }^{30}$ Ibid., 95.

${ }^{31}$ Ibid., 91.

${ }^{32}$ Ibid.
} 
pada muridnya lebih dipusatkan pada praktek lapangan secara langsung. Kendati demikian, tidak dinafikan adannya proses pemberian materi pembelajaran meskipun walau hanya untuk memberi arahanrahan yang akan dilakukan ketika praktik tarekat dilaksanakan.

Dalam kitab Tanwir al-Qulb dijelaskan beberapa ajaran dasar yang berbentuk praktik; ${ }^{33}$

1. Husyr dar dam, sadar sewaktu bernafas, yaitu, suatu latihan dalam konsentrasi di mana sesorang harus menjaga diri dari kehilafan dan kealpaan ketika keluar masuk nafas supaya hati selalu merasakan kehadiran Allah.

2. Nazhar bar qadam, menjaga langkah, seorang murid yang sedang menjalani khalwat suluk, bila berjalan harus menundukkan kepala sebab memandang kepada aneka ukiran dan warna dapat melalikan dari mengingat Allah.

3. Safar war wathan, melakukan perjalanan di tanah kelahirannya, maknanya adalah melakukan perjalanana bathin dengan meninggalkan segala bentuk ketidaksempurnaannya sebagai manusia menuju kesadaran akan hakikatnya sebagai makhluk yang mulia.

4. Khalwat dar anjuman, sepi ditengah keramaian, khalwat ini dibagi kepada dua, pertama, khalwat lahir, yaitu orang yang

33 Istilah yang ada dalam kitab ini diadopsi dari bahasa Persia bersuluk mengasingkan diri kesebuah tempat tersisi dari masyarakat ramai. Kedua, khalwat bathin, yakni mata hati yang menyaksikan rahasia kebesaran Allah .

5. Yad krad, ingat atau menyebut berzikir terus-menerus mengingat Allah, dilaksanakan secara berjamaah maupun sendiri-sendiri setelah shalat.

6. Baz gasht, kembali memperbarui, yaitu, mengingtat Allah, hal ini dilakukan agar mengendalikan hati agar tidak melantur.

7. Nigah dasyt, waspada, ialah setiap murid harus menjaga hati dan perasaan dari sesuatu walau sekejap ketika melakukan dzikir.

8. Yad dasyt, mengingat kembali, adalah tawajuh (menghadapkan diri kepada Nur Allah, tanpa berkata-kata. $^{34}$

\section{E. KESIMPULAN}

Sufisme memiliki andil yang sangat besar di tubuh bangsa ini, mulai dari penyebaran islam sampai pada adanya pendidikan yang tumbuh dan berkembang dari komunitas sufi yang bisa dinikmati oleh masyarakat luas. Tarekat Qadiriyah berupaya mendidik para muridnya dengan menanamkan penyucian diri. Artinya, lebih konsen untuk perbaikan individu, yang kemudian ajaran ini menjalar di masyarakat sebagai bagian dari khazanah keislaman di Indonesia.

${ }^{34}$ Muliyati, Mengenal \& Memahami Tarekat-Tarekat Muktabarah Di Indonesia, 103-105. 
Berangkat dari itu, diharapkan dari tarekat ini, menghasilkan kualitas manusia yang menyibukkan diri membeangun kompetensi diri baik dari segi spritual maupun intelektual.

\section{Pendidikan}

Tarekat

Naqsyabandiyahmengajarkan kepada murid-muridnya prinsip disiplin beribadah dan ketat menjaga syariat. dengan berbagia metode yang ditempuh oleh tareket tersebut diharapkan dapat membangun kualitas spritual dan juga pemahaman agama yang komperhensif.

\section{DAFTAR PUSTAKA}

Bruinessen, Martin Van, and Julia Day Howell. Urban Sufism. Jakarta: Rajawali Pers, 2008.

Huda, Nor. Islam Nusantara: Sejarah Sosial Intelektual Islam Di Indonesia. Cet. 1. Sleman, Jogjakarta: Ar-Ruzz Media: Didistribusikan oleh Ar-Ruzz Media Group, 2007.

Huda, Sokhi. Tasawuf Kultural: Fenomena Shalawat Wahidiyah. Cet. 1. Yogyakarta: LKiS : Distribusi, LKiS Pelangi Aksara, 2008.

al-Jailany, Abdul Qadir. Fathu ArRabbani Walfaidhu ArRahmani. Baghdad: Dar arRayyan at-Turast, n.d.

Muliyati, Sri. Mengenal \& Memahami Tarekat-Tarekat Muktabarah Di Indonesia. Jakarta: Kencana, 2005.

Mulkhan, Abdul Munir. Neo-Sufisme Dan Pudarnya Fundamentalisme Di Pedesaan. Cet. 1. Yogyakarta: UII Press Yogyakarta, 2000.

Qaḥțānī, Sa'īid ibn Misfar ibn Mufrah. Al-Shaykh 'Abd Al-Qädir Al-
Jülān̄̄ Wa-Ärā'uhu AlI'tiqāì̄yah Wa-Al-Süfìyah: 'ard Wa-Naqd 'alá Daw' 'aqīdat Ahl Al-Sunnah Wa-Al-Jamā'ah. Al-Ṭab'ah 1. al-Riyāḍ: Tawzī' Mu'assasat al-Jarīsī lil-Tawzī', 1997.

Salamah, Ummu. Sosialisme Tarekat Menjejaki Tradisi Dan Amaliah Spritual. Bandung: Humaniora, 2005.

Simuh. Sufisme Jawa: Transformasi Tasawuf Islam Ke Mistik Jawa. Cet. 1. Yogyakarta: Yayasan Bentang Budaya, 1995.

Zulkifli. Sufism in Java: The Role of The Pesantren In The Maintenance Of Sufism In Java. Seri INIS 40. Jakarta: INIS, 2002. 